Supporting Information for

\title{
Quantifying Impact of Intrinsic Flexibility on Molecular Adsorption in Zeolites
}

Alan S. S. Daou ${ }^{1}$, John M. Findley ${ }^{1}$, Hanjun Fang ${ }^{1}$, Salah Eddine Boulfelfel ${ }^{1}$, Peter I. Ravikovitch ${ }^{2}$ and David S. Sholl ${ }^{1, *}$

${ }^{1}$ School of Chemical \& Biomolecular Engineering, Georgia Institute of Technology, Atlanta, GA 30332-0100, USA

${ }^{2}$ Corporate Strategic Research, ExxonMobil Research and Engineering, 1545 Route 22 East, Annandale, New Jersey 08801, United States

*+1-404-894-2822, david.sholl@gatech.edu 
Atom - Framework interactions

Table of Contents

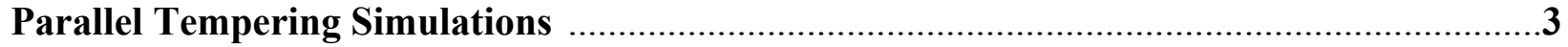

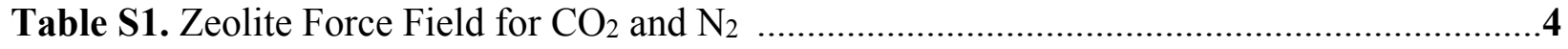

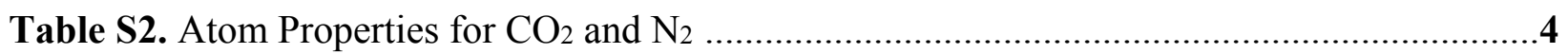

Table S3. Zeolite Force Field for Hydrocarbons …................................................................5

Table S4. Atom Properties for Hydrocarbons ..................................................................5

Figure S1. Parity plot of Henry constants results using NpT and energy minimized structures ...6

Figure S2. Velocity Auto Correlation Function plot for the LTA framework ...........................7

Figure S3. Histogram of the flexible to rigid ratio of single component adsorbed amounts .........8

Figure S4. Ratio and histogram of the Henry constants from flexible and rigid simulations ........9

Figure S5-S7. Flexible to rigid ratio of average mixture loading ..................................... 10-12

Figure S8. Histogram of the flexible to rigid ratio of mixture adsorbed amounts .....................13

Table S5. Value of $\left|\log \left(\mathrm{K}_{\mathrm{F}} / \mathrm{K}_{\mathrm{R}}\right)\right|$ for butane for 11 zeolites ...............................................13

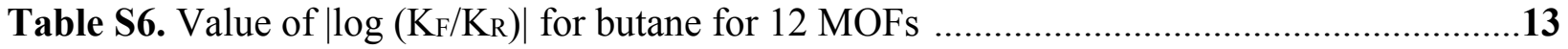




\section{Atom - Framework interactions}

The interactions between $\mathrm{Na}^{+}$and the framework's oxygen atoms are described in the CCFF using the Buckingham² potential:

$$
E\left(r_{i j}\right)=A_{i j} * e^{-B_{i j} * r_{i j}}-\frac{C_{i j}}{r_{i j}^{6}}
$$

All other interactions are defined using the Lennard-Jones ${ }^{3}$ potential:

$$
E\left(r_{i j}\right)=4 \varepsilon_{i j}\left[\left(\frac{\sigma_{i j}}{r_{i j}}\right)^{12}-\left(\frac{\sigma_{i j}}{r_{i j}}\right)^{6}\right]
$$

In these equations, $\mathrm{A}_{\mathrm{ij}}, \mathrm{B}_{\mathrm{ij}}, \mathrm{C}_{\mathrm{ij}}, \sigma_{\mathrm{ij}}$, and $\varepsilon_{\mathrm{ij}}$ are cross-species parameters for species $\mathrm{i}$ and $\mathrm{j}$. The full list of parameters is presented in Tables S1-S4.

\section{Parallel Tempering Simulations}

Parallel tempering simulations ${ }^{4,5}$ were carried out using RASPA $^{6}$ in order to obtain the cation positions for cationic zeolite adsorption. A total of nine structural replicas were propagated in the NVT ensemble at 300, 390, 507, 659, 857, 1114, 1448, 1882, and $2447 \mathrm{~K}$. Each replica was sampled for 500,000 cycles. In order to ensure the convergence of the cation positions for the simulation, 3 different initial configurations were generated for the simulations. Coulomb and van der Waals interactions were treated as in GCMC simulations. 
Table S1. Zeolite Force Field for $\mathrm{CO}_{2}$ and $\mathrm{N}_{2}$.

\begin{tabular}{|c|c|c|c|c|}
\hline $\mathrm{CO}_{2}$ model & \multicolumn{4}{|l|}{$\mathrm{EPM}^{7}$} \\
\hline $\mathrm{N}_{2}$ model & \multicolumn{4}{|l|}{ 2LJ3CB.MSKM ${ }^{8}$} \\
\hline Mixing rules & \multicolumn{4}{|l|}{ Lorentz- Berthelot } \\
\hline Correction & \multicolumn{4}{|c|}{ Truncated potential with tail correction } \\
\hline Force Field Parameters ${ }^{9}$ & Interaction Model & $\mathbf{\varepsilon} / \mathbf{k}_{\mathrm{B}}(\mathbf{K})$ & \multicolumn{2}{|l|}{$\sigma(\AA)$} \\
\hline $\mathrm{C}_{\mathrm{CO} 2}-\mathrm{O}_{\text {zeo }}$ & Lennard-Jones & 29.116 & \multicolumn{2}{|l|}{3.193} \\
\hline $\mathrm{C}_{\mathrm{CO} 2}-\mathrm{Si}_{\mathrm{zeo}}$ & Lennard-Jones & 49.754 & \multicolumn{2}{|l|}{3.620} \\
\hline $\mathrm{O}_{\mathrm{CO} 2}-\mathrm{O}_{\mathrm{zeo}}$ & Lennard-Jones & 23.433 & \multicolumn{2}{|l|}{3.067} \\
\hline $\mathrm{O}_{\mathrm{CO} 2}-\mathrm{Si}_{\mathrm{zeo}}$ & Lennard-Jones & 38.900 & \multicolumn{2}{|l|}{3.494} \\
\hline $\mathrm{C}_{\mathrm{CO} 2}-\mathrm{Na}_{\mathrm{zeo}}$ & Lennard-Jones & 66.778 & \multicolumn{2}{|l|}{2.827} \\
\hline OcO2-Nazeo & Lennard-Jones & 54.762 & \multicolumn{2}{|l|}{2.707} \\
\hline $\mathrm{C}_{\mathrm{CO} 2}-\mathrm{Al}_{\text {zeo }}$ & Lennard-Jones & 32.215 & \multicolumn{2}{|l|}{3.366} \\
\hline OCO2-Alzeo & Lennard-Jones & 25.323 & \multicolumn{2}{|l|}{3.246} \\
\hline $\mathrm{C}_{\mathrm{CO} 2}-\mathrm{C}_{\mathrm{CO} 2}$ & Lennard-Jones & 28.129 & \multicolumn{2}{|l|}{2.757} \\
\hline $\mathrm{O}_{\mathrm{CO} 2}-\mathrm{O}_{\mathrm{CO} 2}$ & Lennard-Jones & 80.507 & \multicolumn{2}{|l|}{3.033} \\
\hline $\mathrm{N}_{2}-\mathrm{O}_{\text {zeo }}$ & Lennard-Jones & 27.31 & \multicolumn{2}{|l|}{3.14} \\
\hline $\mathrm{N}_{2}-\mathrm{Si}_{\text {zeo }}$ & Lennard-Jones & 46.00 & \multicolumn{2}{|l|}{3.57} \\
\hline $\mathrm{N}_{2}-\mathrm{Na}_{\text {zeo }}$ & Lennard-Jones & 82.64 & \multicolumn{2}{|l|}{2.659} \\
\hline $\mathrm{N}_{2}-\mathrm{Al}_{\text {zeo }}$ & Lennard-Jones & 39.51 & \multicolumn{2}{|l|}{3.71} \\
\hline \multirow[t]{2}{*}{$\mathrm{N}_{2}-\mathrm{N}_{2}$} & \multirow[t]{2}{*}{ Lennard-Jones } & 36.4 & \multicolumn{2}{|l|}{3.32} \\
\hline & & $\mathbf{A}(\mathbf{K})$ & $\mathbf{B}\left(\AA^{-1}\right)$ & $\mathrm{C}(\mathrm{K})$ \\
\hline $\mathrm{Na}_{\text {zeo }}-\mathrm{O}_{\text {zeo }}$ & Buckingham & 37850656.24 & 3.8506 & 526402.05 \\
\hline
\end{tabular}

Table S2. Atom Properties for $\mathrm{CO}_{2}$ and $\mathrm{N}_{2}$.

\begin{tabular}{lll}
\hline & Mass (amu) & Charge (amu) \\
\hline $\mathbf{C}_{\mathbf{C O} 2}$ & 12.0 & 0.6512 \\
$\mathbf{O}_{\mathbf{C O} 2}$ & 15.9994 & -0.3256 \\
$\mathbf{N}_{\mathbf{2}}$ & 14.0067 & -0.40484 \\
$\mathbf{N}_{2}$ Center of mass & 0 & 0.80968 \\
$\mathbf{O}_{\text {zeo }} \mathbf{S i}$ & 15.9994 & -1.1062 \\
$\mathbf{O}_{\text {zeo }}{ }^{\mathbf{a l}}$ & 15.9994 & -1.3211 \\
$\mathbf{S i}_{\text {zeo }}$ & 28.0855 & 2.2124 \\
$\mathbf{A l}_{\text {zeo }}$ & 26.981539 & 2.0833 \\
$\mathbf{N a}_{\text {zeo }}$ & 22.98977 & 0.9987 \\
\hline
\end{tabular}


Table S3. Zeolite Force Field for Hydrocarbons.

\begin{tabular}{|c|c|c|c|}
\hline $\mathrm{CH}_{4}$ model & TraPPE $^{10}$ & & \\
\hline Butane model & TraPPE $^{10}$ & & \\
\hline Mixing rules & Lorentz- Berthelot & & \\
\hline Correction & Shifted potential & & \\
\hline Force Field Parameters ${ }^{11}$ & Interaction Model & $\varepsilon / \mathbf{k}_{\mathbf{B}}(\mathbf{K})$ & $\sigma(\AA)$ \\
\hline $\mathrm{CH}_{4} \mathrm{sp} 3-\mathrm{O}_{\text {zeo }}$ & Lennard-Jones & 115 & 3.47 \\
\hline $\mathrm{CH}_{3}-\mathrm{sp} 3-\mathrm{O}_{z е о}$ & Lennard-Jones & 93 & 3.48 \\
\hline $\mathrm{CH}_{2}-\mathrm{sp} 3-\mathrm{O}_{\mathrm{zeo}}$ & Lennard-Jones & 60.5 & 3.58 \\
\hline $\mathrm{CH}_{4}-\mathrm{sp} 3-\mathrm{Na}_{z e o}$ & Lennard-Jones & 582.17 & 2.72 \\
\hline $\mathrm{CH}_{3}$ sp33-Nazeo & Lennard-Jones & 443.73 & 2.65 \\
\hline $\mathrm{CH}_{2}-\mathrm{sp} 3-\mathrm{Na}_{z e o}$ & Lennard-Jones & 310 & 2.95 \\
\hline $\mathrm{CH}_{4} \_\mathrm{sp} 3-\mathrm{CH}_{3} \_\mathrm{sp} 3$ & Lennard-Jones & 130.84 & 3.74 \\
\hline $\mathrm{CH}_{4}-\mathrm{sp} 3-\mathrm{CH}_{2}-\mathrm{sp} 3$ & Lennard-Jones & 94.21 & 3.84 \\
\hline $\mathrm{CH}_{3}-\mathrm{sp} 3-\mathrm{CH}_{2}-\mathrm{sp} 3$ & Lennard-Jones & 77.7 & 3.86 \\
\hline $\mathrm{Na}_{\text {zeoo- }}-\mathrm{O}_{\text {zеo }}$ & Lennard-Jones & 23 & 3.4 \\
\hline $\mathrm{Na}_{\text {zeoo- }}-\mathrm{Na}_{\text {zeo }}$ & Lennard-Jones & 124.4 & 2.16 \\
\hline $\mathrm{CH}_{4} \_\mathrm{sp} 3-\mathrm{CH}_{4}-\mathrm{sp} 3$ & Lennard-Jones & 158.5 & 3.72 \\
\hline $\mathrm{CH}_{3}-\mathrm{sp} 3-\mathrm{CH}_{3}-\mathrm{sp} 3$ & Lennard-Jones & 108 & 3.76 \\
\hline $\mathrm{CH}_{2}-\mathrm{sp} 3-\mathrm{CH}_{2}-\mathrm{sp} 3$ & Lennard-Jones & 56.0 & 2.95 \\
\hline
\end{tabular}

Table S4. Atom Properties for Hydrocarbons.

\begin{tabular}{lll}
\hline & Mass (amu) & Charge (amu) \\
\hline $\mathbf{C H} \mathbf{H}_{4} \_\mathbf{s p 3}$ & 16.04246 & 0 \\
$\mathbf{C H} \mathbf{H}_{\mathbf{3}} \mathbf{s p 3}$ & 15.03452 & 0 \\
$\mathbf{C} \mathbf{H}_{2} \_\mathbf{s p 3}$ & 14.02658 & 0 \\
$\mathbf{O}_{\text {zee }} \mathbf{S i}$ & 15.9994 & -1.025 \\
$\mathbf{O}_{\text {zeo }}$ & 15.9994 & -1.20 \\
$\mathbf{S i}_{\text {zeo }}$ & 28.0855 & 2.05 \\
$\mathbf{A l}_{\text {zeo }}$ & 26.981539 & 1.75 \\
$\mathbf{N a}_{\text {zeo }}$ & 22.98977 & 1.00 \\
\hline
\end{tabular}




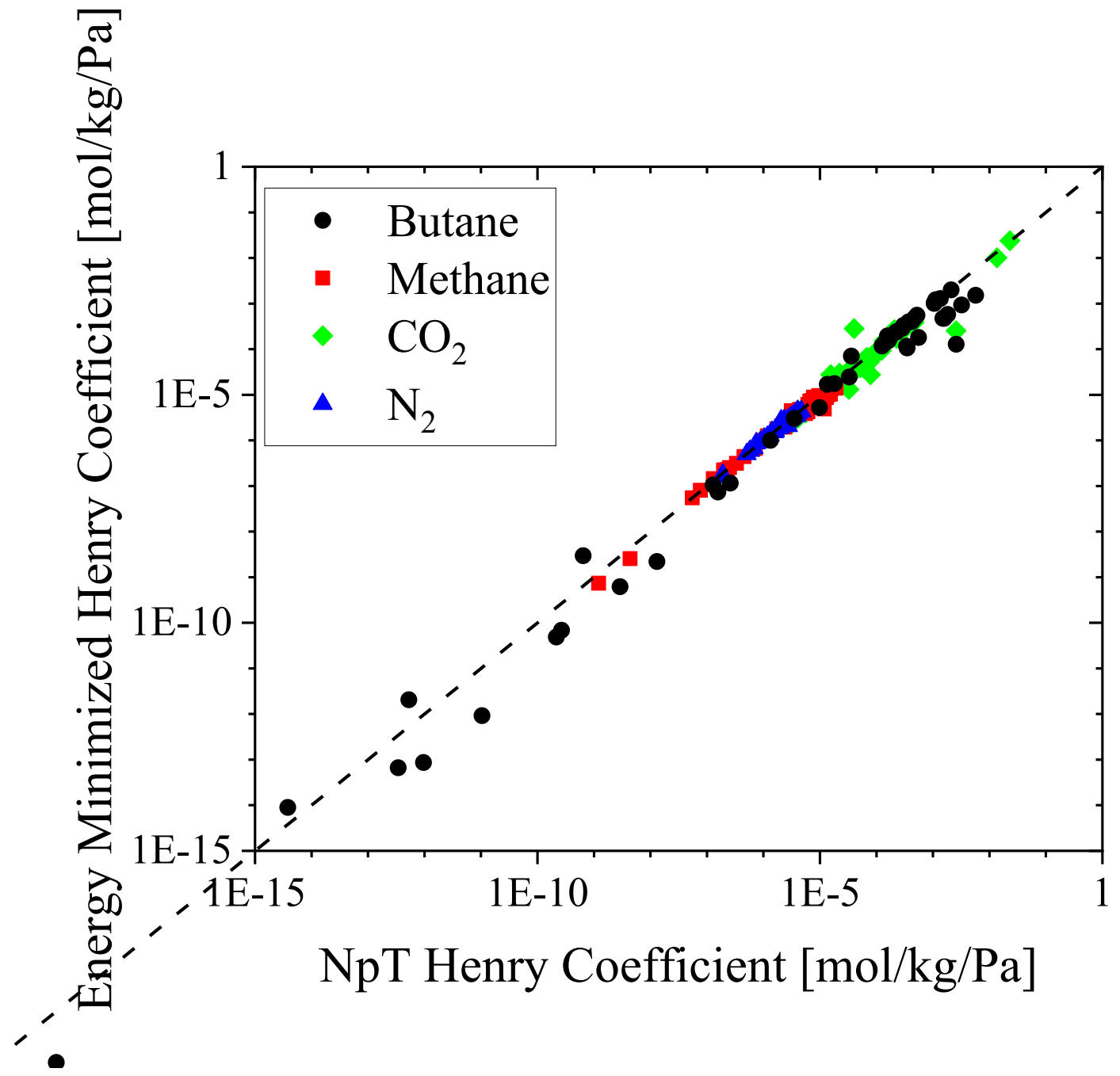

Figure S1. Parity plot of Henry Coefficients results using a single zeolite structure from an NpT simulation of the empty framework (horizontal axis) and energy minimized zeolite structures (vertical axis). 


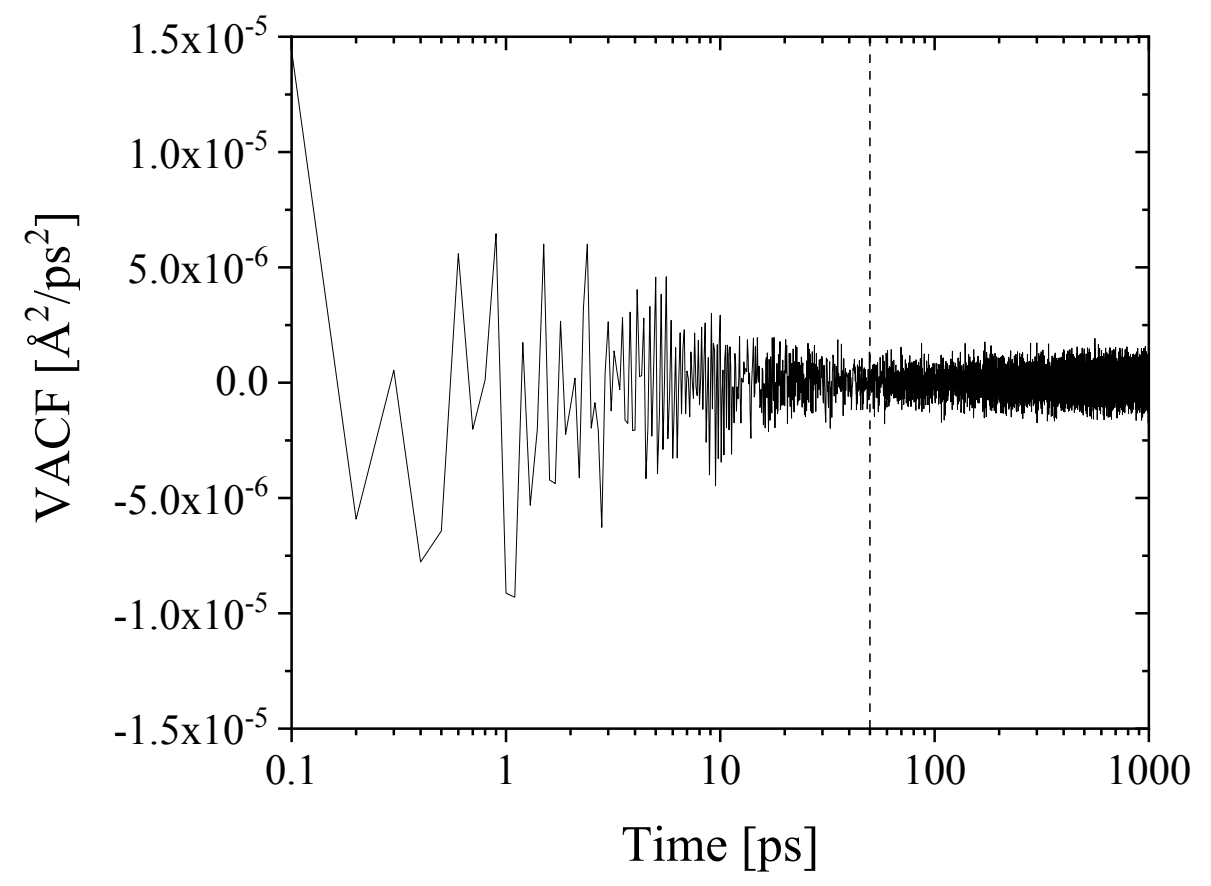

Figure S2. Velocity Auto Correlation Function plot for the LTA framework during the NVT simulation. Dashed line represents the 50 ps mark. 


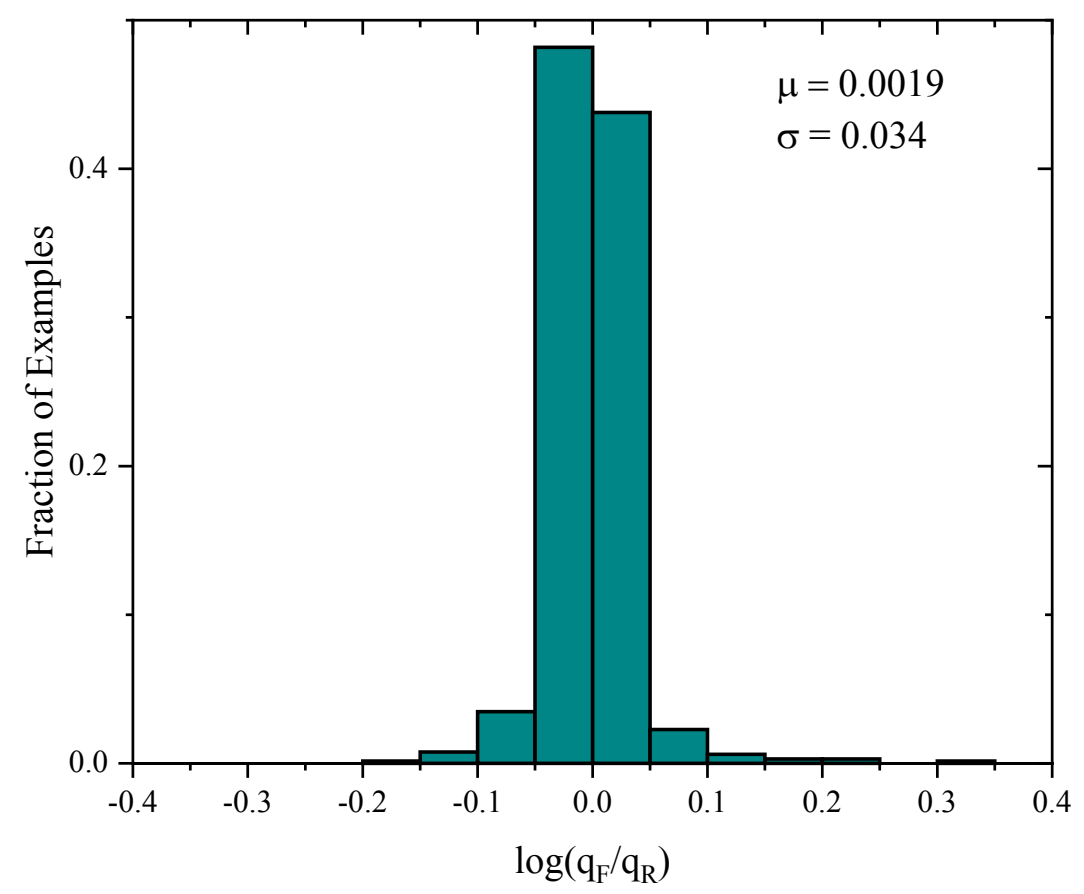

Figure S3. Histogram of the ratio of single component adsorbed amounts, using rigid ( $\mathrm{qR}$ ) and flexible (qF) simulations results for all adsorbates in the 11 silica zeolites at $300 \mathrm{~K}$. The mean $(\mu)$ and standard deviation $(\sigma)$ of the histogram are noted in the legend. 

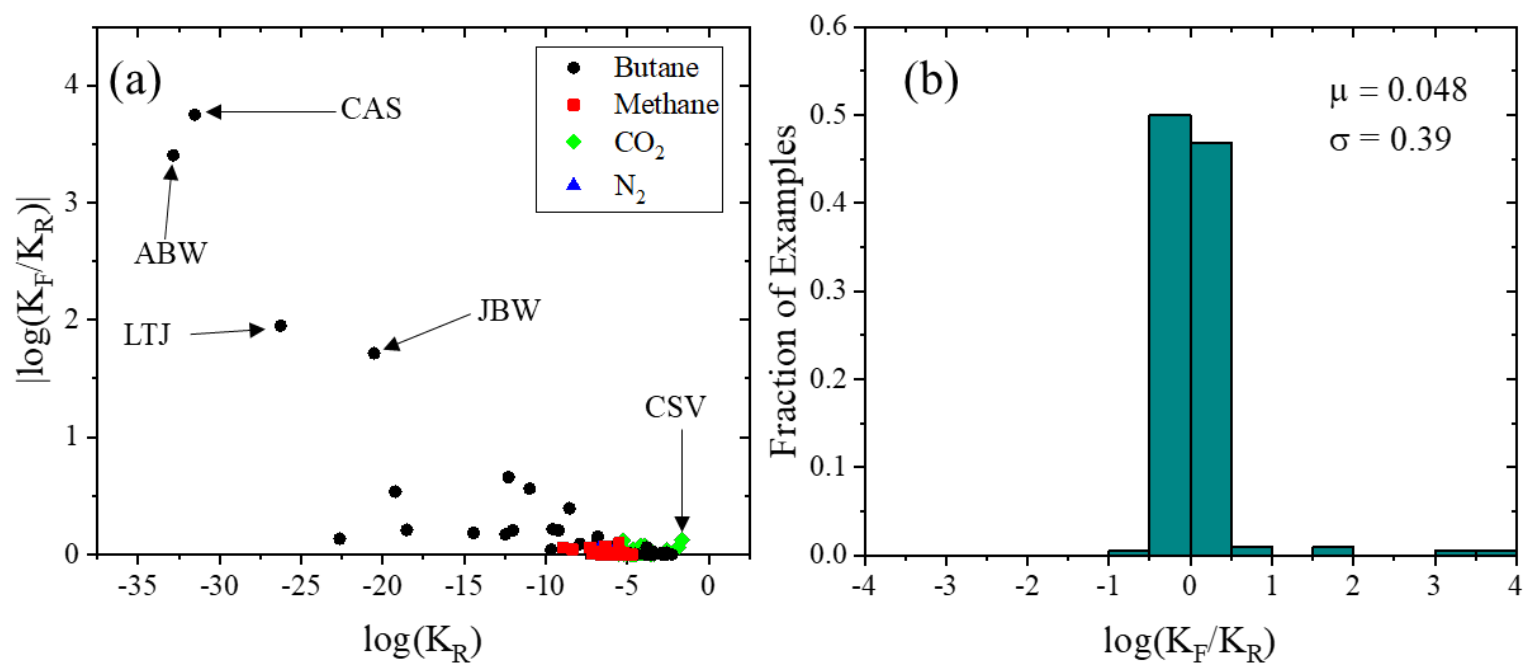

Figure S4. (a) Ratio as a function of value and (b) histogram of the ratio of $300 \mathrm{~K}$ Henry constants from flexible $\left(\mathrm{K}_{\mathrm{F}}\right)$ and rigid simulations $\left(\mathrm{K}_{\mathrm{R}}\right)$ in 55 silica zeolites. The mean $(\mu)$ and standard deviation $(\sigma)$ of the histogram are noted in the legend. Notable zeolites are indicated on the plot 


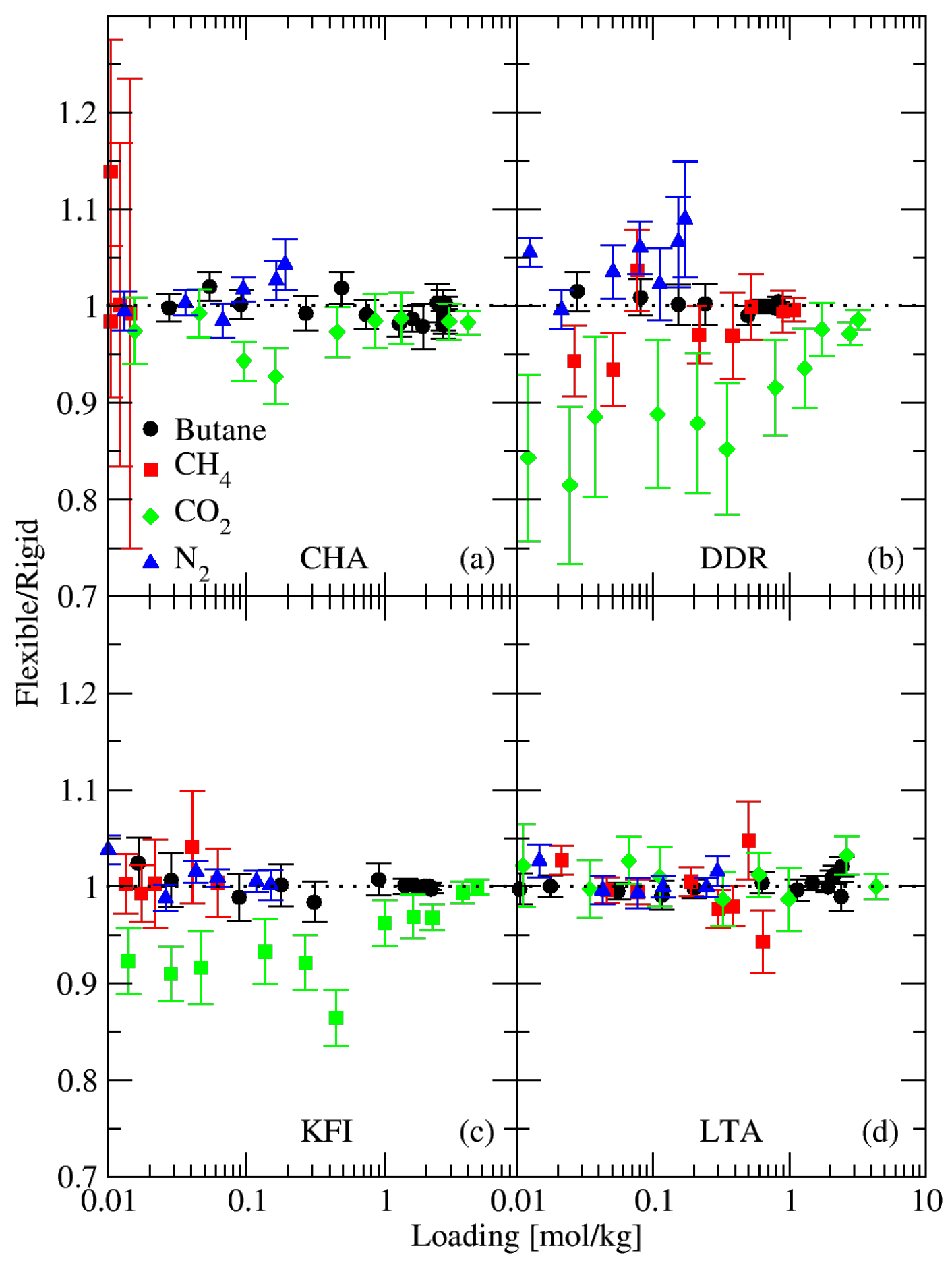

Figure S5. Ratio of average mixture loading of the snapshots to the loading in the rigid structures for adsorption of $\mathrm{CO}_{2} / \mathrm{N}_{2}$ and butane $/ \mathrm{CH}_{4}$ mixtures in pure silica (a) $\mathrm{CHA}$, (b) DDR, (c) KFI, and (d) LTA at $300 \mathrm{~K}$. 


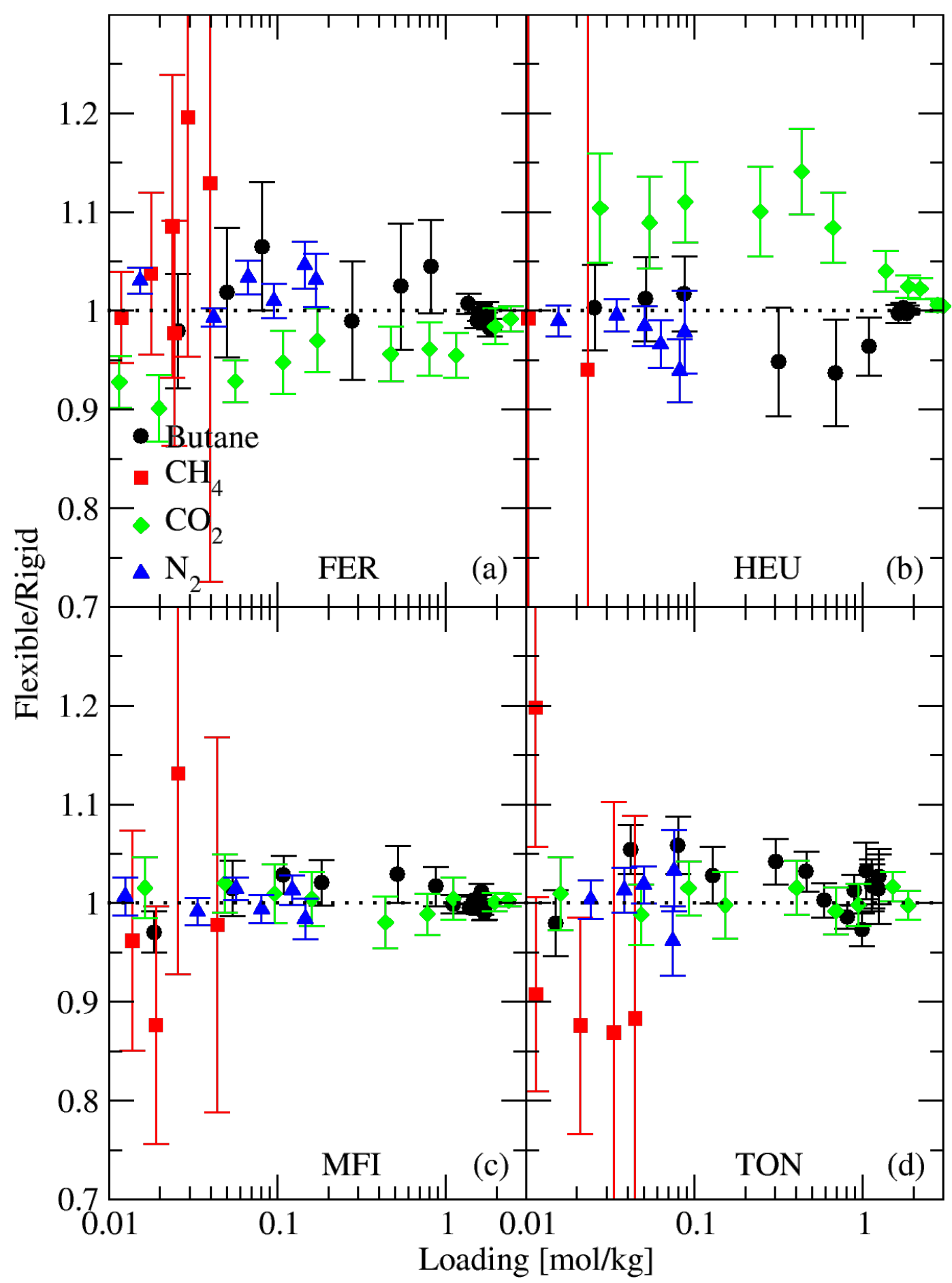

Figure S6. Ratio of average mixture loading of the snapshots to the loading in the rigid structures for adsorption of $\mathrm{CO}_{2} / \mathrm{N}_{2}$ and butane $/ \mathrm{CH}_{4}$ mixtures in pure silica (a) FER, (b) $\mathrm{HEU}$, (c) MFI, and (d) TON at $300 \mathrm{~K}$. 


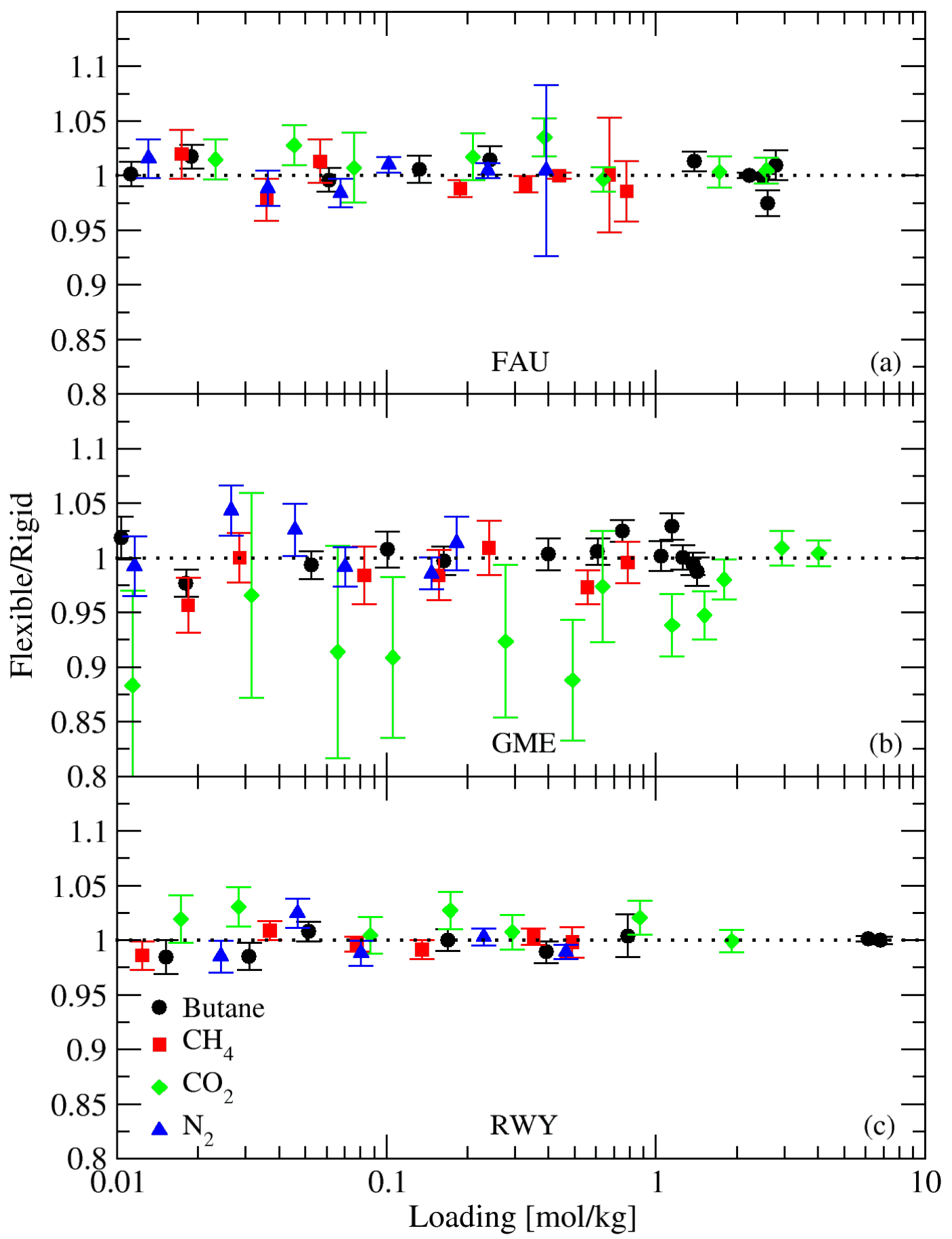

Figure S7. Ratio of average mixture loading of the snapshots to the loading in the rigid structures for adsorption of $\mathrm{CO}_{2} / \mathrm{N}_{2}$ and butane $/ \mathrm{CH}_{4}$ mixtures in pure silica (a) FAU, (b) RWY, and (c) GME at $300 \mathrm{~K}$. 


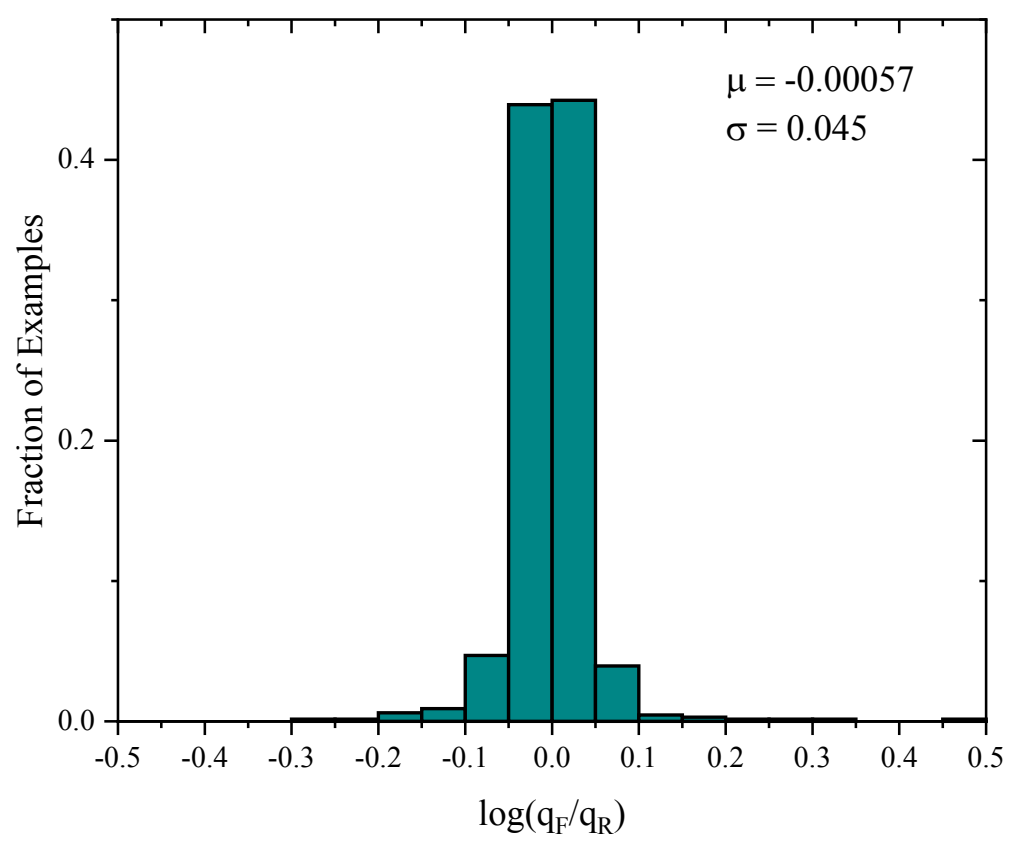

Figure S8. Histogram of the ratio of equimolar mixture adsorbed amounts $\left(\mathrm{CO}_{2} / \mathrm{N}_{2}\right.$ and butane $\left./ \mathrm{CH}_{4}\right)$, using rigid $\left(\mathrm{q}_{\mathrm{R}}\right)$ and flexible $\left(\mathrm{q}_{\mathrm{F}}\right)$ simulations results for all adsorbates in the 11 silica zeolites at $300 \mathrm{~K}$. The mean $(\mu)$ and standard deviation $(\sigma)$ of the histogram are noted in the legend.

Table S5. Value of $\left|\log \left(\mathrm{K}_{\mathrm{F}} / \mathrm{K}_{\mathrm{R}}\right)\right|$ for butane for 11 zeolites at $300 \mathrm{~K}$.

\begin{tabular}{|l|l|l|l|l|l|l|}
\hline Framework & LTA & CHA & DDR & KFI & MFI & FER \\
\hline$\left|\log \left(\mathrm{K}_{\mathrm{F}} / \mathrm{K}_{\mathrm{R}}\right)\right|$ for butane & 0.0039 & 0.0009 & 0.0006 & 0.0076 & 0.0032 & 0.0029 \\
\hline
\end{tabular}

\begin{tabular}{|l|l|l|l|l|l|}
\hline Framework & HEU & TON & FAU & RWY & GME \\
\hline$\left|\log \left(\mathrm{K}_{\mathrm{F}} / \mathrm{K}_{\mathrm{R}}\right)\right|$ for butane & 0.0053 & 0.0007 & 0.0168 & 0.0028 & 0.0004 \\
\hline
\end{tabular}

Table S6. Value of $\left|\log \left(\mathrm{K}_{\mathrm{F}} / \mathrm{K}_{\mathrm{R}}\right)\right|$ for butane for $12 \mathrm{MOF}$ from Agrawal et al. ${ }^{12}$ at $300 \mathrm{~K}$.

\begin{tabular}{|l|l|l|l|l|}
\hline Framework & HAKWUM & CUYHIO & GOMRAC & GUXLIU \\
\hline$\left|\log \left(\mathrm{K}_{\mathrm{F}} / \mathrm{K}_{\mathrm{R}}\right)\right|$ for butane & 62.36 & 64.78 & 0.86 & 40.8 \\
\hline
\end{tabular}

\begin{tabular}{|l|l|l|l|l|}
\hline Framework & AMUCOB & CICYIX & BALMUW & ACOLIP \\
\hline$\left|\log \left(\mathrm{K}_{\mathrm{F}} / \mathrm{K}_{\mathrm{R}}\right)\right|$ for butane & 6.57 & 28.62 & 15.64 & 2.04 \\
\hline
\end{tabular}




\begin{tabular}{|l|l|l|l|l|}
\hline Framework & APEBED & EZUCIM & DOGZIJ & EDADIX \\
\hline$\left|\log \left(\mathrm{K}_{\mathrm{F}} / \mathrm{K}_{\mathrm{R}}\right)\right|$ for butane & 0.1 & 0.03 & 0.03 & 0.51 \\
\hline
\end{tabular}

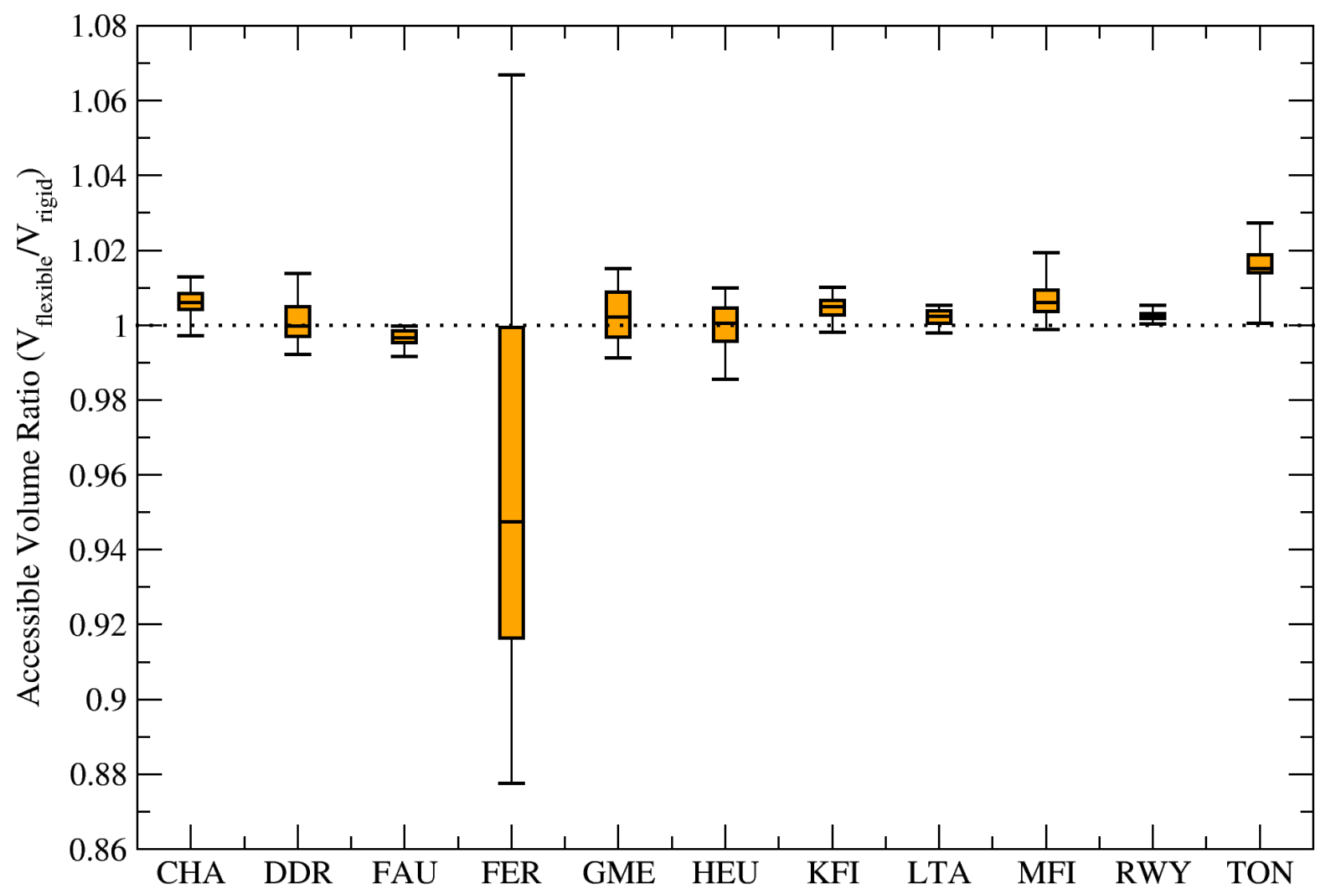

Figure S9. Ratio of accessible volume from flexible snapshots to the accessible volume in the rigid structure for 11 silica zeolites described in the text at $300 \mathrm{~K}$. The upper and lower whiskers represent the range of values while the box is composed of the first quartile, median, and third quartile (from bottom to top).

\section{Plot Data}

The raw data used for the plots throughout the main article as well as the supporting information is available in the Excel file (Supporting_Information.xlsx)

\section{Input Files}

The attached zip file (Input_Files.zip) contains the input files for:

- NPT equilibration (npt.in)

- NVT simulation (nvt.in)

- Energy minimization (lammps.in)

- GCMC adsorption (Adsorption_simulation.input)

- Henry coefficient calculation (Widom_simulation.input) 


\section{References}

1. Fang, H.; Kamakoti, P.; Ravikovitch, P. I.; Aronson, M.; Paur, C.; Sholl, D. S., First principles derived, transferable force fields for $\mathrm{CO}_{2}$ adsorption in Na-exchanged cationic zeolites. Phys Chem Chem Phys 2013, 15 (31), 12882-12894.

2. Buckingham, R. A., The classical equation of state of gaseous helium, neon and argon. Proceedings of the Royal Society of London. Series A. Mathematical and Physical Sciences 1997, 168 (933), 264-283.

3. Lennard-Jones, J. E., On the determination of molecular fields. - II. From the equation of state of a gas. Proceedings of the Royal Society of London. Series A, Containing Papers of a Mathematical and Physical Character 1997, 106 (738), 463-477.

4. Beauvais, C.; Guerrault, X.; Coudert, F. X.; Boutin, A.; Fuchs, A. H., Distribution of sodium cations in faujasite-type zeolite: A canonical parallel tempering simulation study. J Phys Chem B 2004, 108 (1), 399-404.

5. $\quad$ Fang, H. J.; Kulkarni, A.; Kamakoti, P.; Awati, R.; Ravikovitch, P. I.; Sholl, D. S., Identification of High- $\mathrm{CO}_{2}$-Capacity Cationic Zeolites by Accurate Computational Screening. Chem Mater 2016, 28 (11), 3887-3896.

6. Dubbeldam, D.; Calero, S.; Ellis, D. E.; Snurr, R. Q., RASPA: molecular simulation software for adsorption and diffusion in flexible nanoporous materials. Molecular Simulation 2016, 42 (2), 81-101.

7. Harris, J. G.; Yung, K. H., Carbon Dioxides Liquid-Vapor Coexistence Curve and Critical Properties as Predicted by a Simple Molecular-Model. J Phys Chem-Us 1995, 99 (31), 12021-12024.

8. Makrodimitris, K.; Papadopoulos, G. K.; Theodorou, D. N., Prediction of Permeation Properties of $\mathrm{CO}_{2}$ and $\mathrm{N}_{2}$ through Silicalite via Molecular Simulations. The Journal of Physical Chemistry B 2001, 105 (4), 777-788.

9. Hyla, A. S.; Fang, H.; Boulfelfel, S. E.; Muraro, G.; Paur, C.; Strohmaier, K.; Ravikovitch, P. I.; Sholl, D. S., Significant Temperature Dependence of the Isosteric Heats of Adsorption of Gases in Zeolites Demonstrated by Experiments and Molecular Simulations. The Journal of Physical Chemistry C 2019, 123 (33), 20405-20412.

10. Martin, M. G.; Siepmann, J. I., Transferable potentials for phase equilibria. 1. Unitedatom description of n-alkanes. J Phys Chem B 1998, 102 (14), 2569-2577.

11. Calero, S.; Dubbeldam, D.; Krishna, R.; Smit, B.; Vlugt, T. J. H.; Denayer, J. F. M.; Martens, J. A.; Maesen, T. L. M., Understanding the role of sodium during adsorption: A force field for alkanes in sodium-exchanged faujasites. J Am Chem Soc 2004, 126 (36), 11377-11386. 12. Agrawal, M.; Sholl, D. S., Effects of Intrinsic Flexibility on Adsorption Properties of Metal-Organic Frameworks at Dilute and Nondilute Loadings. ACS Appl Mater Interfaces 2019, 11 (34), 31060-31068. 